\title{
Health economics and social medicine: some impressions of an epidemiologist
}

\author{
ROY M. ACHESON \\ From the Department of Community Medicine, University of Cambridge
}

Years ago I was invited to spend some weeks in Japan. On the advice of a friend I read about the history and the culture of the people. Nevertheless I found myself totally unprepared for what I found. Like the Japanese, I was born on a small island in a temperate zone between a continent and a vast expanse of ocean. Through the centuries their ancestors and mine had faced closely similar daily problems not only of survival, but of making survival acceptable, yet the solutions to those problems were bewilderingly different. Brown soup for breakfast, sitting shoeless and cross-legged on the floor in houses which, though glassless, were bright and warm, were never the Irish, nor indeed the English, way. Even the method of catching fish from the sea and the intimacies of personal hygiene were different in Japan.

I was reminded of this when I began seriously to read some health economics before writing this paper. Again the problems were the same, but the approach of health economists to solving them was startlingly different from that of social medicine men. Although I was aware of the rationale of curves of demand and supply, the concepts of maximisation, opportunity costs, and the problems of measuring benefit, I was again unprepared for what I was to find. An example of the economist's unfamiliar approach is Grossman's proposal (1972) that health is an 'investment commodity', a form of capital stock with which one is born; that 'death occurs when the stock falls below a certain level, and ... that therefore individuals "choose" their length of life'. Improbable though it may seem to the work-a-day epidemiologist, Grossman (1972) was able to develop his model in a manner compatible with several aspects of sickness behaviour. A second example is found in the terms Culyer (1971) uses to analyse the forms that the organisation of health care systems should take. He concludes that health care differs from other goods but that itemisation of its differential characteristics (the way in which many social administrators and economists had previously approached the problem) tells us nothing about the most efficient method of producing or allocating it. In social medicine it had never occurred to us that it should. Culyer goes on to explain that this is partly because observation of market imperfection is insufficient to infer inefficiency and partly because choice of an institution is never a choice between a perfect and an imperfect one but between several imperfect ones. The world of the economist, it seems, is twofold. Some, like Grossman, seek to couch explanations of why things happen, such as the incidence of sickness, or the utilisation of health services, in terms of human behaviour-this is the most 'scientific' part of economics and it is often expressed in the formal language of hypotheses and empirical tests. On the other hand, economists are concerned with the direct exploration of values, relative to questions like "what is the proper role of the market in the distribution of health care'?, or 'how many kidney machines should the National Health Service have'?

It is convenient to reduce values to fiscal terms because then they can be added up, but sometimes they elude such reduction, and economists are in the van of those who warn against a 'financial' approach to health care planning. Behaviour ranges from that of identifiable individuals to the subconscious swaying and groping of millions. Sometimes behaviour is looked upon as valuedependent, and sometimes values as behaviourdependent; frequently neither is fixed.

This paper is an attempt to consider health economics from the viewpoint of one worker in social medicine. Because the health economics literature is so large, concentration is limited to a few problems of special interest to him which also seem appropriate for collaborative study between epidemiologists and health economists.

WHAT IS/WAS SOCIAL MEDICINE?

History

It might be helpful in establishing communication between the economist and the practitioner of social medicine to remind ourselves briefly of the origins of social medicine. 
I believe that in Britain social medicine was conceived in the 1930s and born during the Second World War, but its progenitors span several generations and include William Alison, Edwin Chadwick, William Farr, Réné Sand, Henry Sigerist and Andrija Stampar. I believe that although the Society for Social Medicine retains its name, social medicine itself gradually passed away between 1968, when the Todd Commission reported, and 1974, when the National Health Service was reorganised. Now, in 1979, only two or three Chairs in the country still bear the name, and at least one of them combines Social and Community Medicine. The shoulders upon which social medicine stood fairly were the successes of public health. Its concerns were with analysing the reasons for these successes, unravelling the complicated causal patterns of the chronic diseases which the poor as well as the rich were surviving to develop (patterns which have proved to be rooted in society itself), and considering, always in humanitarian, usually in scientific, but sometimes in political terms, how best society could cope with the prevention and management of those diseases. Like the public health movement before it, the social medicine movement was therefore a combination of cold scientific endeavour and warm-blooded activism. The Journal of Social Medicine came into being in 1947 with F. A. E. Crew and Lancelot Hogben as editors and the British Medical Association as publishers. It became the British Journal of Preventive and Social Medicine in 1953 because the term social medicine had political undertones in the United States of America which interfered with sales there. Last year the name changed again to the Journal of Epidemiology and Community Health for the better reason that the publishers and the editorial board unanimously believe that the new title suitably describes the contents for the contemporary reader.

\section{Epidemiology and social medicine}

Social medicine in Britain has been a wholly academic subject, with its practitioners working in university departments or in research units supported by the government. It is no accident that one of the fuw comprehensive British monographs on social medicine, by J. N. Morris (1975), Director of the Medical Research Council Social Medicine Research Unit during its 30-odd years of existence, bears the title 'Uses of Epidemiology', because the chief contribution of social medicine to science in this country has been its research into the natural history and origins of the non-infectious diseases. It was Morris who first used the word epidemiology to describe 'social medicine research' and so brought the relationship between epidemiology and social medicine into line with the earlier relationships between public health and epidemiology. (Acheson 1978a). In order to meet the new challenge, the potential of epidemiology was greatly enlarged by fertile collaboration between statisticians and the medical profession within the Society. As well as throwing light on the causes of infectious and, later, of non-infectious disease, epidemiology has measured the discrepancy between those aspects of disease that the doctor sees in his clinic and the totality of disease in the community.

\section{Does social medicine have a theory?}

A reason given by behavioural scientists for their lack of continued interest in the Society for Social Medicine is that social medicine has no theory (Marinker, 1976; Martin 1977). The major and perhaps the only concerns of the investigator in social medicine are, it is claimed, the collection, analysis, and reporting of data which relate mostly to illness but occasionally to health. If this is true, it places social medicine in stark contrast to economics, which is replete with theory that has been applied not only to the acquisition and provision of health care but to the nature of health itself. But are the critics right?

Community medicine in Britain was the brainchild of the Royal Commission on Medical Education, which suggested that it should have much in common with social medicine-and also with preventive medicine and public health-but should be different from each and all of them. One of several reasons for this difference is that community medicine is a statutorily recognised specialty of medicine, and the Faculty of Community Medicine has stipulated that the practising community physician must appear on the medical register. This limitation was never explicitly or implicitly applied to social medicine.

Time will tell just how important this is.

As its name suggests, social medicine is, nevertheless, an offshoot of medicine itself. It came to life before the days of high technology or soaring health bills, at a time when its original proponents tacitly and unquestioningly accepted as incontrovertible the dedication of medicine to the saving of life at all costs. They extended this concept to the promotion of health among those who, because of ignorance or poverty, were unable to help themselves.

Such truth as there may be in the claim of behavioural scientists that social medicine is a subject lacking theory can perhaps be attributed to the fundamental nature of the theory of social medicine. It is so fundamental that it is taken for granted. 
Like all living things, man treasures life above almost everything else. He may murder to save himself and go to war to protect his society, but unlike other social animals, such as the wolf, the caribou, or migrating birds, he has also learned how to save adult life; most men are prepared to make sacrifices to save the lives of others. From the dawn of history, medicine men have found many ways to practise their arts on individual clients and patients. Then during the last century the causes of infectious disease were discovered and it became possible to control these with procedures which affected whole populations. More often than not, members of these populations were unaware of what was being done, yet the expectation of life was being increased, and its quality enhanced. The specialty concerned with bringing about these changes was variously known at its inception as state medicine or sanitary science but soon afterwards it was called public health.

Social medicine followed by setting out to find means for the prevention and control of the chronic and degenerative diseases which had become more important, in both relative and absolute terms, as the incidence of infection fell. Like public health, its theory was the theory of medicine itself, namely, that survival was to be valued above everything and that all members of society should be given the opportunity to enjoy old age.

Some of its proponents, like John Ryle and J. N. Morris, were medically qualified. Others, such as Richard Titmuss in Britain and Henry Siger ist, Wilbur Cohen, and Isidore Falk in America, were not. In the years after the Second World War, when their message needed most to be heard, the cost of the policies and procedures they proposed was trivial compared with the benefits which were to accrue from them. It is only during the past two decades that the increasing effectiveness and soaring costs of health care have forced those working in clinical and social medicine to consider the implications of limited resources for their practices. This concern of the social physician for the survival of man and his fitness to prosper in his environment has much in common with the concern of the ecologist; indeed, Leslie Banks, who became Reader and then Professor in matters sociomedical in Cambridge in the late 1940s, chose to call his Department 'Human Ecology'. I believe that it can reasonably be suggested that the theory of social medicine and epidemiology has much in common with the theory of human ecology.

This must have some relevance for the economist, for, like him, the ecologist is concerned with behaviour in response to scarce resources: both are concerned with demand and supply and with the interrelationships and balances between crescent and waning systems. As the name social medicine suggests, it has had a special concern with the influence on health of that aspect of the environment of man which is determined by society itself. Sociologists and social administrators are, in my opinion, justified in making the accusations that social medicine has not paid much attention to sociological theory nor, for that matter, contributed much to it, or indeed to social policy. They are wrong, however, to classify social physicians* as unthinking stamp collectors.

\section{THE NATURE OF NEED}

If there has been a single difficulty standing in the way of the establishment of a working understanding between economists and social physicians, it is their respective views of demand and need. The theory of the economist is predicated on the view that a fundamental determinant of behaviour is the cost in terms of time, money, or other foregone desirable things, that people are willing to pay as they demand supplies to satisfy their wants. Much of economics is an analysis of how limitations affect the relationship between demand and supply.

The social physician, for his part, starts with the knowledge that medical technology is available which will improve the quality of life of people who are unaware that such technology exists. He acts in the knowledge that society wishes those of its members who are deprived to benefit; he sees it as his role to identify the deprived and to categorise their requirements. It is for this reason that he has developed epidemiology. By analysing causal pathways he can point the way to prevention, and by epidemiological experiment he can evaluate the effectiveness of a variety of forms of medical care. All this is motivated by his having learned from his own research that among those who demand medical care some suffer little and do not therefore have much to gain from such care, while there are others who demand nothing yet stand to benefit greatly if care is made available to them. This lack of coterminosity between demand and need is ably analysed by Spek (1973); Williams (1974a) develops Spek's analysis further and seeks to demonstrate that although demand cannot be a form of need, need is a form of demand. But Williams, with colleagues, has suggested that because the word 'need' is abused and misunderstood it should 'be banished from discussion of public policy'. (Culyer et al., 1971). Be all of that as it may, debasement of a word is no reason for suggesting that the state it was coined to describe does not exist. If it does *The term social physician, which is used in this paper to avoid clumsiness of expression, designates all those who have practised social medicine. 
exist, failure to recognise it will not send it away. It seems that economists in recent years have been moving away from a market-dominated philosophy of human behaviour, in particular recognising that isolated wants may be an insufficient basis for policy function, and that the public's information (or its absence) is crucial to an understanding of the doctor patient relationship.

The existence of the state known as need is essentially a social judgement, and has been defined in terms of behaviour. Sociologists see in the sick a parallel to people who for some reason cannot or do not conform to the behavioural norms or expectations of the culture to which they belong. Therefore the term deviance has been used for the behaviour of the acutely ill and maladaptation for that of the chronic sick.

This is a useful starting point because it begs neither of two difficult questions, namely (i) who is to recognise when or in whom a state of need exists and (ii) what the need is for. The answer to the first question will be determined by the society concerned. In most societies it could be the individual, his relatives, or a casual passer-by. Some societies commission doctors, nurses, social workers and others to seek out the 'deviant' and 'maladapted' and offer them health care which in the end may prevent, cure, or merely comfort, but which, it is to be hoped, is nevertheless a benefit. A difficulty is that the norms and expectations of behaviour vary greatly between one society and another.

Finding a satisfactory answer to the second question has been and must continue to be the essence of medical practice. Culyer (1976) refers to the need for water of a thirsty man in the desert. That man may be neighbour to another equally thirsty man, but the second, because the cause of his thirst, as well as the heat, is cholera, will benefit not at all from just drinking water. Although he may not himself realise it, his need is also for salt given in such a way that his body can retain it. The decision about what his need is for has therefore to be reached by someone who knows some medicine. If the cholera sufferer had lapsed into the unconsciousness characteristic of his disease and was unable to ask for a drink he would still be in need, although he depended upon the passer-by to recognise it. Culyer's point, of course, is the philosophical one that someone, other than the thirsty man, must recognise the need. Mine is that that may still not be enough, that there may be times when that other person must also be able to identify the reason for the need and understand how it can effectively be met.

The contribution of the economist to the philosophy of the social physician has also been a basis for conflict between them. The economist is not satisfied with the implication that because ill health has been shown to exist, something must be done about it. He argues that if acceptable plans are to be made for providing health services, information should be obtained about the amenability of need to health care, and, if it proves to be amenable, about the costs involved in meeting it. His professional philosophy leads him to balk at the idea of investing resources if the investment is not to be profitable. As a social physician, while I accept the desirability of identifying amenable need (Acheson 1978b), I am happy also to accept the 'loaded' nature of the word itself, and would be reluctant to substitute 'amenable exigency' or any similar euphemism.

\section{THE MEASUREMENT OF HEALTH STATUS AND OF NEED \\ Multidimensional measures of health}

As Culyer et al. (1971) pointed out, in what has already become a classic paper, the development of systems for measuring health status (the units of which are in the authors' terminology 'state indicators'), and studying the distribution of these in the general population, is a natural field for collaboration between research workers in health economics and social medicine. Inasmuch as these indicators point to departure from perfect health, they provide the basis for an index of need. If they are measured serially in an individual or a group of individuals they allow the quantification of benefit, or the lack of it, so they hold promise as a basis for measuring benefits in the context of cost-benefit analysis. Their use in populations by epidemiologists should be helpful in the development of multidimensional isoquants of the type that Culyer and his colleagues propose (1971). Despite their great theoretical appeal one suspects, however, that with current technology and the resources which are likely to be available for research in the foreseeable future it is unlikely that much progress will be made in the development of isoquants, or of examining their distribution in the community at large as a basis for locating those who are in poor health and/or for quantifying their need.

Social physicians and clinicians in collaboration with statisticians over the past 30 years have completed hundreds of randomised trials which have firmly established the effectiveness of some preventive and curative procedures and the worthlessness of others. More recently, in collaboration with economists, similar studies have taken account of efficiency. Such work has therefore been concerned with the effectiveness and efficiency of treatment 
or service. In the terms used by Donabedian (1973), it processes need, rather than being concerned with need itself, but it could be used as a means for identifying amenable need.

\section{Priority indices}

Empirical studies of the susceptibility of need to health care have been far less plentiful, although proposals on how to do this have been made. One was the development by the United States Public Health Service of a Q-index of need in the context of planning health services for the Indian Reservation (Michael et al., 1968). Amenability was not explicitly defined, but it was measured by using the mortality rate for the condition in question. This was age-adjusted to, and divided by, the mortality rate for the same condition in the rest of the population of the USA. The rationale was that when the ratio exceeded unity, the death rate in the Indian population should be considered to be amenable to reduction, provided that resources were appropriately invested.

A second method was the Health Priority Index (HPI) of the Pan American Health Organisation (PAHO) (Stewart, 1968). A panel of experts was invited to assign scores to conditions which indicated tractability to health care, explicit attention being given to preventability. The Q-index of the USPHS assigned top priority to cardiovascular disease; cancer came fourth and infective and parasitic conditions sixth among the Indians. The PAHO used a somewhat different grouping procedure from the USPHS for diseases but their HPI produced a very different ranking in a rural part of Venezuela where dysentery came first, cardiovascular disease fourth, and cancers eighth. The extent to which these differences are due to method or to the need of the populations themselves is therefore difficult to say. Clearly procedures which were developed for deprived populations are not suitable for direct application to cultures with a higher standard of living, but in the absence of other work something can be learned from them. The systematic listing and ranking of amenable need by diagnosis, procedure, and cost would certainly be a useful exercise. The prevalence of and location of amenable need defined in these terms could then be studied in the community at large. The Table shows an example of a first step, subsequently modified and developed, in identifying some forms of amenable need. This was prepared by Hagard (1978) for the Cambridgeshire Area Health Authority (Teaching). The conditions he lists are some which he considers to be amenable to behavioural change directed by health education and social policy. Indices of need based on work of this kind with an attempt to evaluate cost and 'pay-off' are more likely to be of value to planners than those based on mortality data, or even on aggregations of morbid conditions, which are unqualified by amenability or cost. If firm estimates of cost and benefit can be taken into account, so much the better.

\section{THE CLINICIAN AS AN ALLOCATOR OF} RESOURCES

It is claimed that among the most abundant spenders of the money allocated to health is the clinician himself in his daily work. It is he who decides whether a hospital bed is to be filled or whether a major surgical procedure is more likely to be beneficial than prolonged reliance on drugs. He has a controlling influence, should he choose to exert it, over the national drug bill, and directly determines the use of a wide variety of diagnostic procedures which involve the deployment of a large manpower force and costly equipment. Rose (1977) has recently pointed out that doctors faced with a stock diagnostic problem have a stock reaction. A standard battery of tests and investigations are brought to bear which may vary a little between one doctor and another but are determined to no great extent by the case. This rather uncritical largesse dates back to the immediate postwar era. Then, because of the new National Health Service, it became possible at last to investigate a case properly without fear of driving the patient, the hospital, or both, to bankruptcy. Since then the situation has been aggravated by the ever increasing repertoire of the investigative laboratories. Critical path analyses of clinical decision-making have been drawn up and the complicated logic of diagnosis has been described (Murphy, 1976; Wulff, 1976). But cost-benefit studies are now needed of the various diagnostic procedures themselves. Arrow (1973), in his efforts to explain in terms of the market the behaviour of the doctor and his patient and the basis of communication between them, is much more generous to the medical profession than many sociologists who have considered the same questions. The field is a sensitive one. It is difficult to see how the clinician can possibly justify the faith his patient places in him and discharge his tasks responsibly unless he is allowed the complete freedom of action he treasures so highly. Yet for the patient, for the doctor himself, and, because of the spending power referred to above, for society at large, there must be 'best decisions' and these must be reached as effectively and efficiently as possible. The suspicion should never arise that they are the work of a whimsical autocrat. 
The medical profession is cautiously experimenting with medical audit as a means for ensuring that this does not happen. It is to be hoped, however, that clinicians will turn to epidemiologists, economists, and perhaps sociologists, for help in improving the way they go about making their decisions. The potential savings, in terms of inconvenience and sometimes discomfort to the patient as well of money to the country, which may be forthcoming from willing collaboration in this field, are probably enormous.

\section{USES OF RESOURCES :}

HEALTH MANPOWER PLANNING

\section{Cost of health manpower}

The matters so far discussed concern both economists and social physicians who, because of differing philosophical outlooks and assumptions, have approached these questions in different ways, sometimes without a proper understanding of the others' viewpoints. On the subject of the best use of medical manpower, the social physician and the health economist probably stand closer together, although that is not to say that the social physicians' views necessarily coincide with those of the medical profession as a whole. The fundamental question is not how many doctors or nurses should there be, but what should doctors and nurses do? Therefore manpower research is already a potential field for collaboration. It is also a field in which, apart from the work of the Royal Commission on Medical Education (1968) and of Maynard and Walker $(1977 ; 1978)$, little has been done in Britain compared with the United States of America and the developing countries; and these three studies have been more concerned with 'How many'? than 'What'? However, the use of manpower in health services is closely influenced by cultural values, so research into it in one setting is not readily applicable to another. The principles at issue are the same, but the context of the work differs.

In the USA uncoordinated but highly technological medicine is practised in circumstances in which the doctor is at liberty to gear his own pace of work to suit the amount of money he wants to make. Reinhardt (1974) may well be right in suggesting that the physician in the USA makes less use than he might of paramedical assistance simply to add variety to his own day. The American physician is not part of a system which attempts to offer equity of access to all comers; indeed, he has been trained in the belief that he is not doing his work properly if his clinical consultations with new patients do not last from 30 minutes to a full hour. At the other end of the spectrum, in developing countries, much effective treatment for common diseases is provided in minutes, on a rule of thumb basis, by semi-skilled health aides. Of the $£ 5500$ million budget in the National Health Service, $£ 1000$ million goes towards the salaries of nurses and $£ 284$ million towards the salaries of doctors; in all that is to say $25 \%$ of the whole. The assumptions upon which this huge and costly labour force has come into being, and upon which projections for its future are based, have not received the objective scrutiny that is merited. Few would disagree with the view that the most important determinant of the activities of our doctors and nurses is tradition, some of which is derived from premises which no longer obtain. The powerful forces of the self-protection which goes with professionalism are also relevant. Like clinical freedom and decisionmaking, the topic is a delicate one, yet it is difficult to see how the medical and nursing professions, together with the general public in its roles as patient, taxpayer, and member of society, can avoid benefiting if steps are taken towards tidying up an untidy state of affairs.

\section{Task substitution in primary care}

It is some 20 years since Richard Scott et al. (1960) first drew attention to the fact that the general practitioner spends over $60 \%$ of his time in therapeutic listening, that is, lending a sympathetic ear to patients with conditions for which pharmaceuticals, as often as not, are unnecessary. There are various norms in general practice, among them the list size of about 2400 and the expectation that each patient should have an average of five minutes of the doctor's time. These norms are presumably tacitly predicated on the expectation that GPs should continue with their therapeutic listening. It seems that the estimates of medical manpower needs which have led, in the past decade, to the opening of four new medical schools and to increasing the size of many others are similarly predicated. Many general practitioners believe that much of the therapeutic listening they do is an improper use of their time, as is their frequent visiting of the aged and the chronic sick; and I agree with them. These jobs must be done, but how often should they be done by doctors? Could this work be shared? GPs argue that they do not have the best opportunity to use the long expensive training they underwent. Many of them would like to concentrate their attention on matters with which they and they alone are competent to deal. It is currently fashionable on both sides of the Atlantic to talk about the primary care team. Hicks (1976) came out strongly in favour of it in his monograph on primary care commissioned by 
the Department of Health and Social Security, and at least one health area in England has formulated a policy of working towards a general establishment of primary care teams with three members, of whom the general practitioner would be primus inter pares, in each.

This is laudable. But will task-substitution between members of the team then take place? Will the GP devote more time to new or difficult cases? Will the practice size be increased? Even if only half his therapeutic listening and some of his routine visiting can be taken off his hands, he should enjoy a considerable increase in the time he has to spare for other tasks he really wants to do and still be able to increase the size of his list. These are not the only tasks doctors can delegate. We must not lure the ablest of our young people into medicine unless we are satisfied that their abilities will be suitably exploited.

\section{Manpower for preventive medicine}

Forward looking people have long questioned whether it is necessary for those on the medical register to immunise children against infectious diseases, and McDonough (1977) has recently reported on a programme in Yorkshire in which the various professional groups concerned have agreed that this work can be performed by health visitors. The extent of public acceptance and the general success of the scheme are indicated by the fact that over 150000 children have participated without any untoward consequences and the acceptance rate has been over $90 \%$, which is a very long way above the national average.

The assumption, more often tacit than explicit, that the general practitioner's colleagues in the primary care team will be a health visitor and a community nurse, should not be allowed to go unchallenged. Workers trained in these fields may prove to be ideal but they may not. Their professional origins and traditions can certainly be traced to a time and to circumstances which bear little relevance to the present. However, there is more to task-substitution than thinking in terms of 'the nurse doing the doctor's work' (Acheson, 1977). The randomised controlled trials are well known that provide evidence for the usefulness in general practice in Ontario of a new grade of health worker, the nurse practitioner (Sweeny and Hay, 1973; Sackett et al., 1974; Spitzer et al., 1974), but these could usefully be extended to consider cost and benefit on a wider basis. In Britain and elsewhere a case can be made for the establishment of a career grade of preventive health workers whose responsibility would be to deal with aspects of mass screening and immunisation. Attempts could usefully be made to determine whether, if part of the health manpower force were specifically trained in this field alone, beneficial programmes could be completed which are now too costly to be contemplated with the professional personnel currently available. Satisfactory evidence along these lines could perhaps lead to a new approach to the training of health workers.

\section{Physician extenders}

All of us are grateful from time to time to have recourse to the advice and attention of a medical expert whose specialty could be primary care or otorhinolaryngology or anaesthesia, and we will continue to count on their availability. In the long run it may turn out that the optimum mix between such experts and others, whom Fuchs (1974) describes as 'physician extenders', may be similar everywhere; perhaps modifying factors such as population structure and density may have to be taken into account. Perhaps also there may be a continuum of skills within the health professionals of the kind Fuchs (1974) hints at as being desirable. It is, however, salutary to remember that the two-tiered system of physician and feldsher in the USSR is not generally considered to be wholly felicitous, and that both in India and Pakistan a lower tier of medical practitioner, the subassistant surgeon inherited from Imperial days, has created enough pressure for ways to be found for the ? members of the lower tier to become 'proper doctors', so that the grades of licensed medical practitioner and licentiate of the medical faculty have disappeared. Moreover in many parts of America means have been found of absorbing osteopaths into the fold of organised medicine. Training an upper and a lower grade of doctor is evidently not the answer.

\section{Differing national solutions}

Whatever the long-term solution may be, the road towards it will be different in each country. Engineering this road will be a highly complex business. It will involve the consideration of appropriate tasks and roles, the tactful modification of public attitudes as well as those of all existing health professionals, and a great many experiments to assess the merits of alternative approaches. The social physician, the health economist, and other behavioural scientists will be involved in the mapping and the construction. What it amounts to is assessing the best pay-off for investment in the training of a mixed labour force of several hundred thousand workers. The investment is first made in the secondary schools, training colleges, and universities, but the interest will not accrue for many 
decades because it will be measured in terms of the health of those for whom the trainees of tomorrow will eventually provide care. Thus, analysis of cost and benefit in the usual sense will be valueless; what is required is the development of continuing procedures for evaluation.

Fundamental questions have yet to be asked and answered, firstly, about the appropriateness of the medical curriculum to the skills used and the tasks undertaken by members of the various specialties in the ordinary working day, and, secondly, about how many of those skills are best deployed by people who have gone through the long processes of medical education and how many would be better lodged with 'lay specialists'. Descriptive epidemiological surveys, controlled trials, and cost-effectiveness analyses, are among the procedures needed to come to grips with the problem.

\section{OTHER PROBLEMS: QUALITY OF CARE AND}

\section{SOCIAL COSTS OF ILLNESS}

Neither space nor time permit the discussion of two other problems of importance to social physicians, the solutions of which will not be feasible without close collaboration with economists. Firstly, there is the question of the evaluation of the quality of output of health facilities ranging from those with a specific role, where the problem should be relatively simple, such as a day centre for the elderly, to the more complex, such as health centres and hospitals. The second problem is how best to evaluate the indirect and social costs of illness, particularly when the patient is cared for in his home. The statement has frequently been made in official documents and elsewhere that care is cheaper at home than in hospital, but this has yet to be clearly demonstrated. Economists, with their very broad concept of cost, are surely welcome as both experts and propagandists in this territory.

\section{CONCLUSION}

The investigator who becomes interested in any of the issues discussed above will probably find that in the end he is on the path towards cost-benefit analysis, so I would like to finish by quoting Alan Williams (1974b), who wrote: 'The trouble with the more comfortable [forms of analysis] is that they foster the illusion that, if cost-benefit analysis is not done, the issues which it poses can be avoided, whereas the reality is that these issues are still present, and they still have to be resolved. If health services planning is not to be based on the principle that unwitting decisions are likely to be better than witting decisions, the cost-benefit approach must become part of every decision maker's intellectual equipment'. I am confident in the prediction that members of the Society for Social Medicine will find collaborative endeavour with economists in this field as fruitful a means for advancing knowledge and developing scientific method as the collaboration between epidemiologists and statisticians which took place in the Society's early years.

\section{Comment: ROBIN SHANNON \\ Lecturer in Economics \\ University of Newcastle-upon-Tyne*}

Acheson argues that the fundamental concern of the social physician is for the survival of man and his fitness-a lovely Darwinian word-to prosper in his environment. He concludes that the underlying theory of social medicine has a great deal in common with human ecology. Economists, too, have applied their analytical tools to ecology and have found a number of revealing isomorphisms between economics and population biology or sociobiology. The biologist Wilson (1975) has gone so far as to suggest that all the social sciences might be seen as a subdivision of the all-encompassing field of sociobiology, and, as one of the founding fathers of modern economics, Alfred Marshall, put it, ¿. . economics has no near kinship with any physical science. It is a branch of biology broadly interpreted' (Marshall, 1920).

Hirshleifer (1977) has recently pointed out that the isomorphism between economics and population biology involves two levels of analysis. At the first level, acting units or entities (be they men or earthworms) choose (or behave as if they choose) strategies to develop techniques that promote success in the struggle or competition for advantage in given environments, a process which the economist usually calls 'optimising' and the biologist 'adapting'. Formally, the processes are of constrained maximisation.

At the second, higher level of analysis, the social or aggregate consequences of the interaction of the striving units or agents are analysed. The formalisation here is found in the equations of static or dynamic equilibrium. Of course, the solutions on the two levels are interdependent. 'The pursuit of advantage on the part of acting units takes place subject to the opportunities and constraints that emerge from the social context, while the resulting social configuration (which is part of the environment for each separate agent) depends in turn upon the strategies employed by the advantage-seeking entities' (Hirshleifer, 1977), (be they men or caribou).

This, I think, clarifies the contention of Acheson that sometimes economists see behaviour as valuedependent, and sometimes values as behaviour-dependent; 'frequently neither is fixed', as he says. Indeed, economists delight in working with interdependent systems, as do ecologists and social physicians. Nevertheless economists generally have had strikingly little to say about the formation of preferences; other social scientists have not been backward, however, in jumping in where economists have feared to tread.

*At the time of the Cambridge meeting in $1978, \mathbf{R}$. S. was at the Medical Care Research Unit of the University of Newcastle-uponTyne. 
I see the position of economics vis-à-vis other areas of social study, including social medicine, as ideally one of inter-penetration rather than division into inviolable territories. The rôle of economics will not be one of a gradual imperialistic takeover of the other social sciences. Economics has more closely become sociology, political science, or social medicine, as the techniques of economic analysis have come to consider any subject matter which can be seen as goal-directed behaviour constrained by, yet in the aggregate determining, resultant social configurations. Examples are many; they are to be found among many others in the work of Boulding (1962) on conflict and warfare; in Becker $(1968 ; 1973)$ on crime, marriage and the economics of the family; and more recently in Fair (1978) on the economic theory of extramarital affairs. At the same time, as other disciplines such as sociology become more rigorous, they will tend to become 'economics'. This gradual forward movement towards fusion in the pursuit of truth will not, of course, happen overnight, but it should lead to a co-operative division of labour between economists and practitioners of social medicine.

The concept of co-operation needs further explanation. Ghiselin (1974) distinguishes between the competitive division of labour represented by the subdivision of ecological niches in the biological sphere, corresponding to product or locational differentiation in the economy, and the co-operative division of labour. In the former case (which economists might call competitive specialisation) there is no mutual dependence or complementarity among the entities. Each would be better off if the other were to vanish. In the latter, co-operative type of division of labour is, however, a true alliance-to achieve a common end, or at least for mutual benefit where a complementarity exists. This is how the economist/social physician relationship will most usefully develop.

A fascinating model presented by Wilson (1975) illustrates the potentially unfortunate consequences of non-co-operation. The question for the entity is one of choice between so-called ' $K$ ' strategies and ' $N$ ' strategies, $\mathbf{K}$ and $\mathbf{N}$ being demographic parameters. $\mathbf{K}$ symbolises the carrying capacity of the environment (defined as the species number $\mathrm{N}$ at a time when $\frac{\mathrm{dN}}{\mathrm{dt}}=0$ ) and $r$ symbolises the maximum rate of Malthusian growth, obtaining under conditions under which the environment is not constraining.

Species which are designated $\mathbf{r}$ are opportunists, who pioneer and settle new unfilled environments (in the context of this paper could they be economists? or are they the social physicians?). The $\mathrm{K}$ strategists are less adventurous, and more averse to risk; they compete by superior effectiveness in utilising the resources of relatively saturated environments. The $r$ strategists make their living from the recurrence of dis-equilibrium situations (entrepreneurial types), but their success can only be transient; ultimately they are kicked off-stage by the far more efficient $\mathrm{K}$ strategist species. The $r$ strategists tend to be characterised by high early mortality, and they must continuously disperse and take big risks to find fresh, unsaturated environments. A high birth rate is therefore necessary. Other tendencies are rapid maturity, small body size, early reproduction, and short life. $K$ strategists, by contrast, have slower development, larger body size, and longer life; and an inclination to produce a smaller number of more carefully optimised offspring.

Table An analysis of the amenability of various conditions to control by changes of behaviour and other measures*

\begin{tabular}{|c|c|c|c|c|c|c|c|c|c|c|c|}
\hline $\begin{array}{l}\text { Need arising from risk } \\
\text { from morbidity from: }\end{array}$ & & & & & & & & & & & \\
\hline $\begin{array}{l}\text { Ischaemic heart disease } \\
\text { Lung cancer } \\
\text { Chronic bronchitis } \\
\text { URT infections in children } \\
\text { Dental disorders } \\
\text { Musculoskeletal disorders } \\
\text { Accidents } \\
\text { Venereal disease } \\
\text { Unwanted pregnancies } \\
\text { Neurosis } \\
\text { Alcoholism } \\
\end{array}$ & $\begin{array}{r}++ \\
+ \\
+ \\
+ \\
+ \\
+ \\
+ \\
\end{array}$ & $\begin{array}{r}++ \\
+ \\
+ \\
+\end{array}$ & ++ & $\begin{array}{r}+ \\
++ \\
\end{array}$ & $\begin{array}{l}+ \\
+\end{array}$ & + & + & + & ++ & $\begin{array}{r}+ \\
+ \\
+ \\
?+\end{array}$ & $?+$ \\
\hline $\begin{array}{l}\text { Preventive measures based } \\
\text { on health education }\end{array}$ & 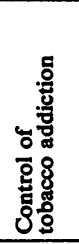 & 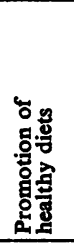 & 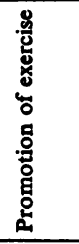 & 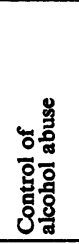 & 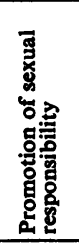 & 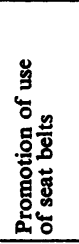 & 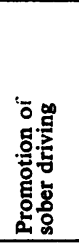 & 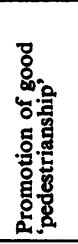 & 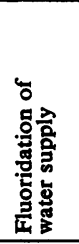 & 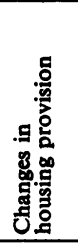 & 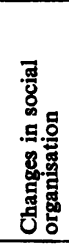 \\
\hline $\begin{array}{l}\text { Amenable to following action } \\
\text { Locally based health } \\
\text { oducation programmes } \\
\text { Nationally based health } \\
\text { education programmes } \\
\text { Changes in taxation } \\
\text { Changes in law } \\
\text { National policy development }\end{array}$ & $\begin{array}{r}+ \\
++ \\
++\end{array}$ & $\begin{array}{l}+ \\
+ \\
+ \\
+\end{array}$ & $\begin{array}{l}+ \\
+ \\
?+\end{array}$ & $\begin{array}{r}+ \\
+ \\
+\end{array}$ & $\begin{array}{l}+ \\
+\end{array}$ & $\begin{array}{r}+ \\
++\end{array}$ & $\begin{array}{r}+ \\
+ \\
++\end{array}$ & $\begin{array}{r}+ \\
+ \\
++\end{array}$ & $\begin{array}{r}+ \\
++\end{array}$ & ++ & ++ \\
\hline
\end{tabular}


I would hope that this particular analogue is not the most appropriate for analysing the relationship between our two groups. The potential gains through cooperation are far too valuable to be thrown away in a destructive competitive division of our labour.

In discussing the development by economists of indexes for measuring health status, Acheson writes that despite their theoretical appeal he expects little real progress to be made in the development of isoquants as a means for measuring health status. I share his scepticism to some extent. We economists must be very careful not to oversell ourselves and our wares. To do so can only lead to disappointment and disillusion in the future. Mooney (1979) rightly stresses the value of the economist's contribution to a philosophy of thought, a framework of analysis, instead of to the construction of a precise and magnificent machine for turning out answers correct to the nth decimal place.

Acheson goes on to discuss Table 1 (Hagard, 1978) listing conditions which are held amenable to behavioural change directed by health education and social policy. I agree that the identification and ranking of amenable need by diagnosis, procedure, and cost is more likely to be of value to planners than crude indices based on mortality or even morbidity unqualified by amenability or cost, but his Table nicely raises some crucial issues. In my view it positively invites the essential contribution of the economist: the analytical separation of judgements of value from statements of fact. The value of the work of Culyer et al. (1971) was that it showed at precisely which stages in the decision-making process valuations are required, and raised the elemental issue of who should make them. Its strength was not in providing a cook-book recipe for producing sets of real numbers which would tell someone what to do. It would be a great pity if economists were expected in the near or even middle future to come up with uncontroversial ready-for-use numbers called health indices.

When he turns his attention to health manpower planning, Acheson contrasts the seeming lack of research in this area in the United Kingdom vis-à-vis the United States of America. Maynard and Walker have, however, recently published two useful studies of the UK situation (Maynard and Walker, 1977; 1978). The record of manpower planning in the National Health Service has not been a happy one. Too often a crude 'needs' philosophy has dominated the methodology adopted, with little emphasis on the opportunity costs of training, and virtually none on the alternative effects on the nation's health of either extra doctors, or nurses, or both, or other types of medical manpower.

Finally I would add a warning to my plea for constructive co-operation. There is a real danger that economists' language (or jargon) may be adopted within other disciplines but without a clear understanding of the philosophy of the economist. Nowadays, such sociological terms as exploitation, alienation, and rôle are glibly on the lips of all. Words which perhaps once had clear and rigorous definitions have now become little more than convenient noises. I hope it doesn't happen to economics. But it may be part of the price economics has to pay for its diffusion.
Reprints from Professor R. M. Acheson, Department of Community Medicine, University of Cambridge, Addenbrooke's Hospital, Hills Road, Cambridge CB2 2QQ.

\section{References}

Acheson, R. M. (1977). Primary and community care: past and future. Health and Hygiene, 1, 83-87.

Acheson, R. M. (1978a). The definition and identification of need for health care. Journal of Epidemiology and Community Health, 32, 10-15.

Acheson, R. M. (1978b). Medicine, the community and the University: a century of Cambridge history. British Medical Journal, 2, 1737-1741.

Arrow, K. J. (1973). The welfare economics of medical care. In Health Economics. Edited by M. H. Cooper and A. J. Culyer. Penguin: London.

Becker, G. S. (1968). Crime and punishment: an economic approach. Journal of Political Economy, 76, 169-217.

Becker, G. S. (1973). A theory of marriage. Journal of Political Economy, 81, 813-846.

Boulding, K. E. (1962). Conflict and Defence: A General Theory. Harper and Row: New York.

Culyer, A. J. (1971). The nature of the commodity 'health care' and its efficient allocation. Oxford Economic Papers, 23, 189-211.

Culyer, A. J., Lavers, R. J., and Williams, A. (1971). Social indicators: health. Social Trends, 2, 31-42.

Culyer, A. J. (1976), editor. Need and the National Health Service. Economics and Social Choice, p. 15. Martin Robertson: London.

Donabedian, A. (1973). Aspects of Medical Care Administration. Harvard University Press: Massachusetts.

Fair, R. C. (1978). A theory of extramarital affairs. Journal of Political Economy, 86, 45-62.

Fuchs, V. R. (1974), editor. Who Shall Live? Basic Books: New York.

Ghiselin, M. (1974). The Economy of Nature and the Evolution of Sex. University of California Press: Berkeley.

Grossman, M. (1972). On the concept of health capital and the demand for health. Journal of Political Economy, 80, 223-255.

Hagard, S. (1978). Personal communication.

Hicks, D. (1976). Primary Health Care. HMSO: London.

Hirshleifer, J. (1977). Economics from a biological viewpoint. Journal of Law and Economics, 20, 1-52.

Marinker, M. (1976). The relationship between doctor and patient. In Seminars in Community Medicine. Volume 1: Sociology, p. 37. Edited by R. M. Acheson and L. Aird. Oxford University Press.

Marshall, A. (1920). Principles of Economics. Eighth edition. Macmillan: London.

Martin, F. M. (1977). Social medicine and its contribution to social policy. Lancet, 2, 1336.

Maynard, A., and Walker, A. (1977). Too many doctors? Lloyds Bank Review, 125, 24-36. 
Maynard, A., and Walker, A. (1978). Doctor manpower 1975-2000: alternative forecasts and their implications. $A$ report for the Royal Commission on the National Health Service. HMSO: London.

McDonough, V. P. (1977). Immunisation procedures. Community Health, 9, 41-43.

Michael, J. M., Spatafore, G., and Williams, E. R. (1968). A basic information system for health planning. Public Health Reports, 83, 21-28.

Mooney, G. (1979). Economic approaches to alternative patterns of health care. Epidemiology and Community Health, 33, 48-58.

Morris, J. N. (1975). Uses of Epidemiology, third edition. Churchill Livingstone: London.

Murphy, E. A. (1976), editor. The Logic of Medicine. Johns Hopkins University Press: Baltimore.

Reinhardt; U. E., and Smith, K. R. (1974). Manpower substitution in ambulatory care. In Health Manpower and Productivity. Edited by J. Rafferty. Lexington Books: Massachusetts.

Rose, M. (1977). The objective tangent. Lancet, 2, 1340.

Royal Commission on Medical Education (1968). HMSO: London.

Sackett, D. L., Spitzer, W. D., Gent, M., and Roberts, R. S. (1974). The Burlington randomised trial of the nurse practitioner: health outcomes of patients. Annals of Internal Medicine, 80, 137.

Scott, R., Anderson, J. A. D., and Cartwright, A. (1960). Just what the doctor ordered. An analysis of treatment in a general practice. British Medical Journal, 2, 293-299.

Spek, J. E. (1973). On the economic analysis of health and medical care in a Swedish health district. In The Economics of Medical Care. Edited by M. H. Hauser. Allen and Unwin: London.

Spitzer, W. O., Sackett, D. L., Sibley, J. C., Roberts, R. S., Gent, M., Kergin, D. J., Hackett, B. C., and Olynich, A. (1974). The Burlington randomised trial of the nurse practitioner. New England Journal of Medicine, 290, 251-256.

Stewart, D. (1968). Planning as an integral and essential part of a national health program. Medical Care, 6, 439-453.

Sweeny, G. P., and Hay, W. I. (1973). The Burlington experience: a study of nurse practitioners on family practice. Canadian Family Physician, 19, 101-110.

Williams, A. (1974a). 'Need' as a demand concept (with special reference to health). In Economic Policies and Social Goals. Aspects of Public Choice. Edited by A. J. Culyer. Martin Robertson: London.

Williams, A. (1974b). The cost benefit approach. British Medical Bulletin, 30, 252-256.

Wilson, E. O. (1975). Sociobiology: The New Synthesis. Harvard University Press: Cambridge, Massachusetts. Wulff, H. R. (1976). Rational Diagnosis and Treatment. Blackwell Scientific Publications: Oxford. 